LA-8394-MS

Informal Report

UC-34c

Issued: June 1980

\section{Graphs of the Cross Sections in the Alternate Monte Carlo Cross Section Library at the Los Alamos Scientific Laboratory}

R. E. Seamon

P. D. Soran

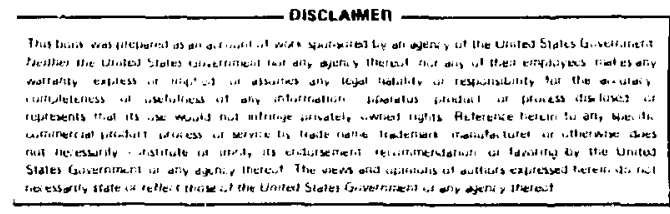




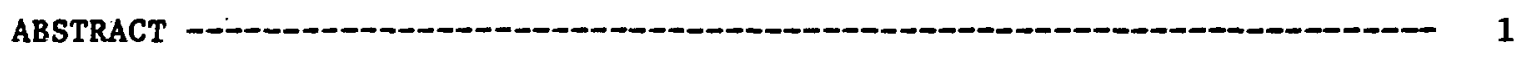

I. INTRODUCTION - 1

II. CONTENTS OF THE VOLUME - 1

III. DISCUSSION - 2

IV. ACKNOWLEDGMENTS

REFERENCES - 4

TABLES :

TABLE I. Isotopes and E zements on AMCCS

TABLE II. Key to the Curves in Figure 1

Figure 1. Data for Prompt $\bar{v}$ on AMCCS

Enclosure: One plece of microfiche titled - (back cover) "AMCCS ZA = 1001 thru 94240" 


\title{
GRAPHS OF THE CROSS SECTIONS IN THE ALTERNATE MONTE CARLO CROSS SECTION LIBRARY AT THE LOS ALAMOS SCTENTIFTC LABORATORY
}

by

R. E. Seamon and P. D. Soran

\begin{abstract}
Graphs of all neutron cross sections and photon production cross sections on the Alternate Monte Carlo Cross Section (AMCCS) library have been plotted along with local neutron heating numbers. The values of $v$, the average number of neutrons per fission, are also plotted for appropriate isotopes.
\end{abstract}

\section{INTRODUCTION}

This report is a inel to Ref. 1 in which the cross sections on the Recommended Monte Carlo Cross Section (RMCCS) 11brary are presented in hard copy format. In this report we provide microfiche containing the same sort of information from the AMCCS library. These cross section files have been prepared for the Monte Carlo neutron-photon transport code MCNP. 2 The format in which the neutron and photon production cross section information is stored on the RMCCS and AMCCS files is described in Appendix E of Ref. 2.

In the same spirit in which the RMCCS cross sections are presented in Ref. 1 , we give here the AMCCS cross section curves with all their "warts and wrinkles," no attempt having been made to smooth the curves, to make polynomial fits to the data, or in other ways to make the curves cosmetically more acceptable. It is true that the negative heating numbers have been cut off as reported In the DISCUSSION section of Ref. 1 .

\section{COXTENTS OF THE WOLURE}

With this volume we present on microfiche the plots of the neutron interaction and photon production cross sections for the 39 elements and 
1sotopes listed in Table $I$. The nuclide identifler name, ZAID, is followed by the chemical symbol for the element or isotope as well as 1 ts elemental name. The source of the evaluation from whic! the data were taken is given as well as information about the temperature at which the cross sections were calculated, the upper and lower energy limits of each cross section set, and the quality of the heating numbers.

The nuclide identifier name zAI! is a floating point number used to identify the evaluation. The portion of ZAID to the left of the decimal point is $Z A$, where $Z A=1000 * Z+A, Z$ is the charge number (atomic number) for the element and $A$ is the mass number; the unique ID Identifler for the cross section set is to the right of the decimal point.

The cross sections on AMCCS come from three sources: the Evaluated Nuclear Data Files ENDF/B-III and ENDF/B-IV, ${ }^{3}$ the Evaluated Nuclear Data Library ENDL, 4 and the Atom1c Weapons Research Establishment L1brary UK. 5

In general, the lower energy limit for the cross section sets is $10^{-5} \mathrm{eV}$ $\left(10^{-11} \mathrm{MeV}\right)$; the upper energy IImit $1 \mathrm{~s} 20 \mathrm{MeV}$; EXCEPTIONS to this rule are noted in Table I.

There are 39 sets of graphs contalned on the microflche, one set for each of the elements or isotopes on the AMCCS file. The arrangement of the graphs is precisely the same as that described for the RMCCS 11 brary in Ref. 1 . We remind our readers that the untt for all cross sections is barns and that for loca? neutron heating is MeV/collision.

\section{DISCUSSION}

One remarkable difference between the AMCCS and RMCCS 11 brarles is that on AMCCS there may be more than one evaluation for a particular 1sotope. Spectf1cal1y, for $235_{U}$ there are seven cross section sets, for ${ }^{238} \mathrm{U}$ there are four sets, and for ${ }^{239} \mathrm{Pu}$ there are six sets. Zloser inspection of Table I shows that many of the sets came from ENDF/B-IV and that the difference between them is the temperature at which the cross sections were calculated. These are "doppler broadened" cross sections. Temperature broadening is carried out in the NJoY 6 code after the pointwise cross sections have been reconstructed from the resonance parameters and background given in the original evaluation.

There are several sets of cross sections with negative heating numbers as shown by the crosses in the last column of Table I. The origin of this difficulty has been revlewed in detall in the DISCUSSION section of Ref. 1 . As 
pointed out there, some of these problems can be explained by the fact that we have mixed together photon production and neutron cross sections from different evaluations. This problem is much more pronounced on the AMccs 11 brary. It should be noted in particular that on the RMCCS library the ENDL evaluations do not have negative heating numbers whereas on the AMCCS' 1 fbrary it appears that they do. It must be emphasized that the footnotes for Table I are very significant; the ENDL evaluations which appear on AMCCS did NOT have photon production information associated with them; we used photon production matrices from other sources in concert with the ENDL neutron cross sections, there was not energy consistency between the neutron and photon data, and the negative heating numbers resulted. The MCNP code does not use the negative heating numbers, but Instead they are set to 0.0 .

The average number of neutrons per fission, $\bar{v}$, is an important quantity which must be displayed for the fissionable isotopes. The curves for prompt and total $\bar{v}$ for the ENDF/B-IV evaluations of $235_{\mathrm{U}}, 238_{\mathrm{U}},{ }^{239} \mathrm{Pu}$, and $240_{\mathrm{Pu}}$ have already been displayed in Append $1 x B$ of $R$ ef. 1 . It remains to display the values of prompt $\bar{v}$ which are provided with the various ENDL evaluations on AMCCS for ${ }^{235} \mathrm{U},{ }^{238} \mathrm{U},{ }^{239} \mathrm{Pu}$, and $240 \mathrm{Pu}$. These curves are shown in Fig. 1; the relationships between the curve labels and the ENDL evaluations are given in Table II. The curves for the two ${ }^{235} \mathrm{U}$ evaluations are essentially indistinguishable and show more variation as a function of energy.

\section{ACRMOULEDGHENTS}

The cross section plots on the micrufiche were generated using program EVALPLOT ${ }^{7}$ modified for use here at LASL. We thank D. E. Cullen for maiking the original version of that program available to lis. We also thank $J$. Briesmeister for her assistance in generating the plots of $\bar{y}$ versus energy and $D$. Morris for secretarial assistance in preparation of the manuscript. 


\section{RBFBRENCES}

1. P. D. Soran and R. E. Seamon, "Graphs of the Cross Sections in the Recommended Monte Carlo Cross Section Library at Los Alamos," Los Alamos Sclentific Laboratory report LA-8374-MS (May, 1980).

2. LASL Group X-6, "MCNP - A General Monte Carlo Code for Neutron and Photon Transport," Los Alamos Sclentific Laboratory report LA-7396-M (November, 1979).

3. D. Garber, C. Dunford, and S. Pearlstein, "Data Formats and Procedures for the Evaluated Nuclear Data File, ENDF," Brookhaven National Laboratory report BNL-NCS-50496 (ENDF-102) (October, 1975).

4. R. J. Howerton, D. E. Cullen, R. C. Hafght, M. H. MacGregor, S. T. Perkins, and E. F. Plechaty, "The LLL Evaluated Nuclear Data Library (ENDL): Evaluation Techniques, Reaction Index, and Description of Individual Evaluations," Lawrence LIvermore Laboratory report UCRL-50400 Vol. 15, Part A (September, 1975).

5. K. Parker, "The Format and Conventions of the U.K.A.E.A. Nuclear Data Library as of May, 1963," Atomic Weapons Research Establishment report AWRE 0-70/63, Aldermaston, England (1963).

6. R. E. MacFarlane, R. J. Barrett, D. W. Muir, and R. M. Bolcourt, "The NJOY Nuclear Data Processing System: User's Manual," Los Alamos Scientific Laboratory report LA-7584-M (ENDF-272) (December, 1978).

7. D. E. Cullen, "Program Evalplot (Version 79-1): Plot Data in the Evaluated-Nuclear-Data-File/Version B (ENDF/B) Format," Lawrence Isivermore Laboratory report UCRL-50400, Vo1. 17, Part E (February, 1979). 
TABLE I

ISOTOPES AND ELEMENTS ON AMCCS

\begin{tabular}{|c|c|c|c|c|c|c|c|}
\hline ZAID & $\begin{array}{c}\text { Chemica1 } \\
\text { Symbol } \\
\end{array}$ & $\begin{array}{c}\text { Element } \\
\text { Name }\end{array}$ & $\begin{array}{c}\text { Evaluation } \\
\text { Source } \\
\end{array}$ & $\begin{array}{c}\text { Temperature } \\
(\mathrm{K}) \\
\end{array}$ & $\begin{array}{l}\text { Lowest } \\
\text { Energy } \\
\text { (MeV) }\end{array}$ & $\begin{array}{c}\text { Highest } \\
\text { Energy } \\
(\mathrm{MeV}) \\
\end{array}$ & $\begin{array}{l}\text { Negative } \\
\text { Heating }\end{array}$ \\
\hline 1001.30 & ${ }^{1} \mathrm{H}$ & hydrogen & *ENDL $-76^{a}$ & 0 & $10^{-10}$ & & $x$ \\
\hline 1002.04 & ${ }^{2} \mathrm{D}$ & deuterlum & $\star E \mathrm{EDF} / \mathrm{B}-\mathrm{IV}$ & 0 & & & $\mathbf{x}$ \\
\hline 1003.30 & ${ }^{3} \mathrm{~T}$ & tritium & ENDL-76 & 0 & $10^{-10}$ & & \\
\hline $2004 \cdot 30$ & ${ }^{4} \mathrm{He}$ & hellum & ENDL-76 & 0 & $10^{-10}$ & & \\
\hline 5010.02 & $10_{B}$ & boron & $\star_{E N D F} / \mathrm{B}-\mathrm{III}^{\mathrm{b}}$ & $\mathbf{b}$ & & 15.0 & \\
\hline $7014 \cdot 30$ & ${ }^{14} \mathrm{~N}$ & nitrogen & ${ }^{*} \mathrm{ENDL}-76^{\mathrm{a}}$ & 0 & $10^{-10}$ & & \\
\hline $8016 \cdot 30$ & $16_{0}$ & oxygen & $* \mathrm{ENDL}-76^{\mathrm{C}}$ & 0 & $10^{-10}$ & & \\
\hline 9019.01 & ${ }^{19} F$ & fluorine & $\star E N D L-73^{a}$ & 0 & $10^{-10}$ & & $\mathbf{x}$ \\
\hline 13027.01 & ${ }^{27} \mathrm{AI}$ & aluminum & *ENDL $-73^{C}$ & 0 & $10^{-10}$ & & $\mathbf{x}$ \\
\hline 14000.01 & $s 1$ & silicon & $* E N D L-73^{c}$ & 0 & $10^{-10}$ & & $\mathbf{x}$ \\
\hline 17000.01 & $\mathrm{Cl}$ & chlorine & *ENDL $-73^{d}$ & 0 & $10^{-10}$ & & $\mathbf{x}$ \\
\hline 20000.01 & $\mathrm{Ca}$ & calcium & $\star E N D L-73^{d}$ & 0 & $10^{-10}$ & & $\mathbf{x}$ \\
\hline 22000.01 & $\mathrm{~T} 1$ & titanium & ENDL -73 & 0 & $10^{-10}$ & & \\
\hline 24000.01 & $\mathrm{Cr}$ & chromium & UK & 0 & $10^{-10}$ & 15.0 & \\
\hline 26000.30 & $\mathrm{Fe}$ & Iron & *ENDL-76C & 0 & $10^{-10}$ & & $\mathbf{x}$ \\
\hline 28000.01 & N1 & nickel & UK & 0 & $10^{-10}$ & 15.0 & \\
\hline 29000.01 & $\mathrm{Cu}$ & copper & *ENDL $-73^{C}$ & 0 & $10^{-10}$ & & $\mathbf{x}$ \\
\hline 40000.01 & $\mathrm{Zr}$ & $z \operatorname{lrconium}$ & UK & 0 & $10^{-10}$ & 17.0 & \\
\hline 41093.01 & ${ }^{93} \mathrm{Nb}$ & nlobium & $E N D L-73$ & 0 & $10^{-10}$ & & \\
\hline 73181.01 & ${ }^{181_{\mathrm{Ta}}}$ & tantalum & ENDL-76 & 0 & $2.5 \times 10^{-8}$ & 14.6 & \\
\hline 82000.01 & $\mathrm{~Pb}$ & lead & ${ }^{\star} E N D L-73^{c}$ & 0 & $10^{-10}$ & & $x$ \\
\hline 92235.01 & $235_{U}$ & uranium & *ENDL-73 & 0 & $10^{-10}$ & & \\
\hline 92235.10 & $235_{U}$ & urantum & *ENDF/B-IV & 0 & & & \\
\hline 92235.11 & $235_{U}$ & uranium & ${ }^{*} \mathrm{ENDF} / \mathrm{B}-\mathrm{IV}$ & 300 & & & \\
\hline 92235.15 & $235 \mathrm{U}$ & urantum & ${ }^{*}$ ENDF / B-IV & $1.2 \times 10^{7}$ & & & \\
\hline 92235.18 & $235_{U}$ & urantum & ${ }^{*}$ ENDF/B-IV & 3000 & & & \\
\hline 92235.20 & $235_{U}$ & urantum & *ENDF/B-IV & $6 \times 10^{5}$ & & & \\
\hline 92235.30 & $235_{U}$ & uranium & *ENDL-76 C & 0 & $10^{-10}$ & & \\
\hline 92238.01 & $238_{U}$ & uranium & *ENDL-73e & 0 & $10^{-10}$ & & $\mathbf{x}$ \\
\hline 92238.15 & $238_{U}$ & uranium & ${ }^{*}$ ENDF/B-IV & $1.2 \times 10^{7}$ & & & $\mathbf{x}$ \\
\hline 92238.20 & $238_{U}$ & uranium & ${ }^{*}$ ENDF / B-IV & $6 \times 10^{5}$ & & & $x$ \\
\hline
\end{tabular}


TABLE I (cont)

\begin{tabular}{|c|c|c|c|c|c|c|c|}
\hline ZAID & $\begin{array}{c}\text { Chemical } \\
\text { Symbol }\end{array}$ & $\begin{array}{l}\text { Element } \\
\text { Name }\end{array}$ & $\begin{array}{c}\text { Evaluation } \\
\text { Source } \\
\end{array}$ & $\begin{array}{l}\text { Temperature } \\
\text { (K) } \\
\end{array}$ & $\begin{array}{l}\text { Lowest } \\
\text { Energy } \\
\text { (MeV) }\end{array}$ & $\begin{array}{c}\text { Highest } \\
\text { Energy } \\
(\mathrm{MeV})\end{array}$ & $\begin{array}{l}\text { Negative } \\
\text { Heating }\end{array}$ \\
\hline 92238.30 & $238_{u}$ & uranium & $\star E N D L-76^{c}$ & 0 & $10^{-10}$ & & \\
\hline 94239.01 & ${ }^{239} \mathrm{Pu}$ & plutonium & $*$ ENDL $-73^{e}$ & 0 & $10^{-10}$ & & $\mathbf{x}$ \\
\hline 94239.15 & ${ }^{239} \mathrm{Pu}$ & plutonium & *ENDF/B-IV & $1.2 \times 10^{7}$ & & & \\
\hline 94239.16 & ${ }^{239} \mathrm{Pu}$ & plutonium & *ENDF / B - IV & 0 & & & \\
\hline 94239.17 & ${ }^{239} \mathrm{Pu}$ & plutonium & ${ }^{*} \mathrm{ENDF} / \mathrm{B}-\mathrm{IV}$ & 300 & & & \\
\hline 94239.18 & ${ }^{239} \mathrm{Pu}$ & plutontum & *ENDF/B-IV & 3000 & & & \\
\hline 94239.20 & ${ }^{239} \mathrm{Pu}$ & plutonium & *ENDF / B - IV & $6 \times 10^{5}$ & & & \\
\hline 94240.01 & $240_{\mathrm{Pu}}$ & plutonium & *ENDL $-73^{e}$ & 0 & $10^{-10}$ & & $\mathbf{x}$ \\
\hline
\end{tabular}

*The asterisk indicates those evaluations for which photon production data are included.

aThe photon production data were taken from ENDF/B-IV.

b The photon production data were taken from a local evaluation by R. E. Seamon described in a memorandum dated June 8, 1973.

${ }^{c_{T}}$ The photon production data were taken from a source other than that from which the neutron cross sections came. The source for the photon production data is not readily identifiable.

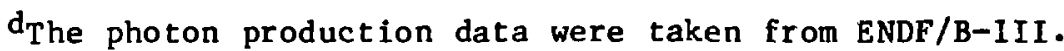

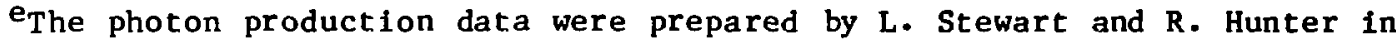
December, 1972.

TABLE II

KEY TO THE CURVES IN FIGURE 1

$\begin{array}{cc}\text { ZAID } & \text { Curve La be1 } \\ 92235.01 & \text { U-235a } \\ 92235.30 & \mathrm{U}-235 \mathrm{~b} \\ 92238.01 & \mathrm{U}-238 \mathrm{a} \\ 92238.30 & \mathrm{U}-238 \mathrm{~b} \\ 94239.01 & \mathrm{Pu}-239 \\ 94240.01 & \mathrm{Pu}-240\end{array}$




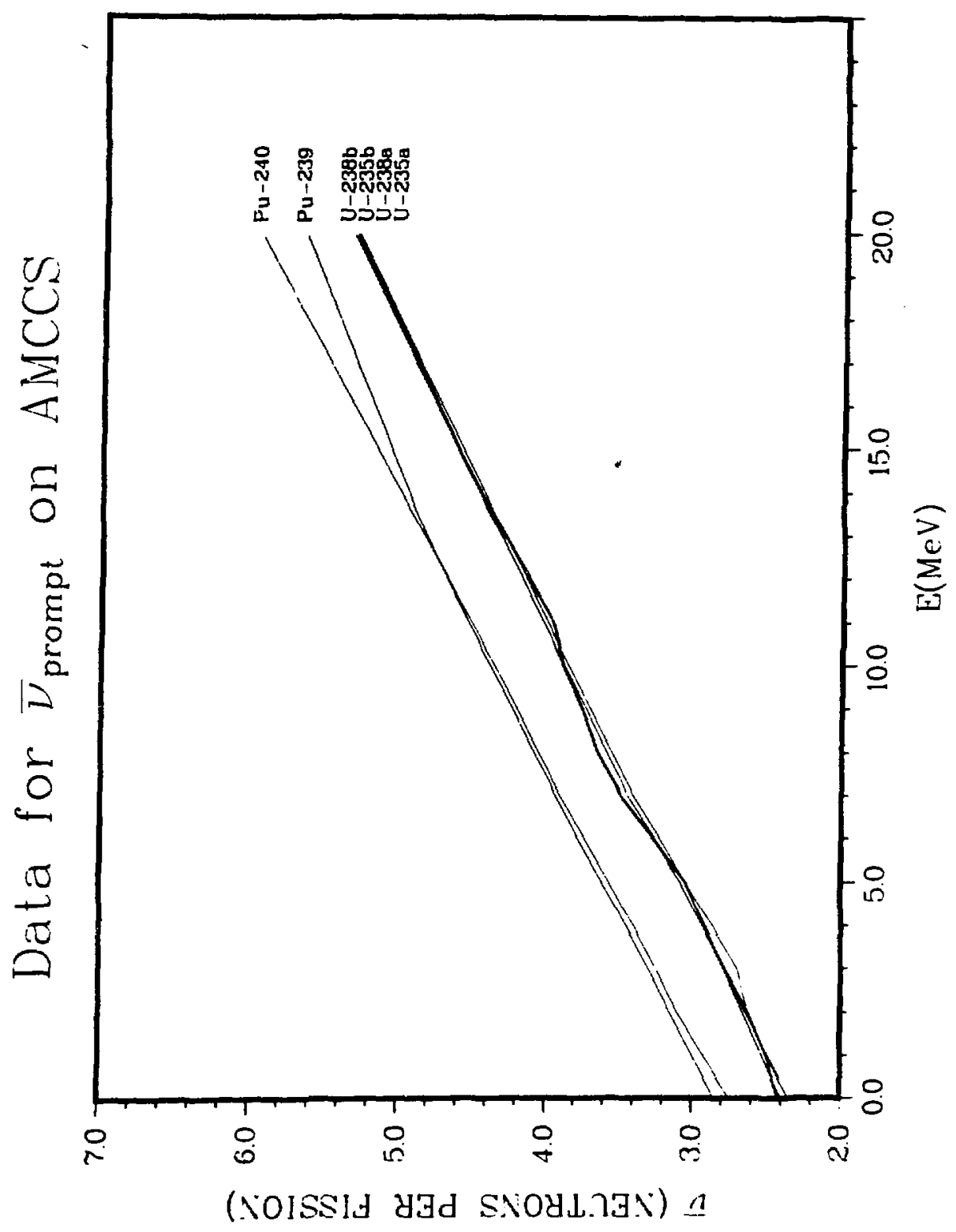

Figure 1.

Data for prompt $\bar{v}$ on AMCCS. 